\title{
Stakeholders' Contribution towards Responsible Innovation in Information and Communication Technology Research Projects
}

\author{
Tilimbe Jiya ${ }^{1}$
}

\begin{abstract}
Information and Communication Technology (ICT) research projects engage stakeholders who contribute towards different aspects of research and innovation. One of the aspects that stakeholders contribute towards in ICT research projects is responsibility. There is a need for those engaged in ICT research projects to take into consideration the impacts of their activities on society as part of responsible research and innovation (RRI) through finding solutions to emerging societal problems and developing sustainable processes of carrying out research and innovation. In this paper, the focus is two-fold. Firstly, I focus on understanding how stakeholders are identified to contribute towards responsibility in ICT research projects and secondly, I focus on how stakeholders contribute towards responsibility in such projects. I conducted an interpretive case study in which data were collected by semi-structured interviews with 11 stakeholders from two ICT research projects. Through thematic data analysis, their perceptions and understanding of their contribution towards responsibility were conceived. From the study findings, I established that there are problems in understanding the meaning of term 'responsibility' among stakeholders which later affects the identification of roles that deal with it. Despite the ambiguity of the meaning, I found that stakeholders contribute towards responsibility in many ways although there are barriers that affect their contribution.
\end{abstract}

Keywords: Responsibility; stakeholder engagement; stakeholder contribution; responsible innovation; ICT research projects

Submitted: Jan $7^{\text {th }}, 2019 /$ Approved: Sep $19^{\text {th }}, 2019$

\section{Introduction}

In recent years there has been an upsurge of technological innovation through ICT research projects. These projects engage an array of stakeholders who are assigned roles that deal with different aspects of the project ranging from financial viability to social sustainability. One of such aspects is 'responsibility'. Responsibility is a fundamental aspect of research and innovation (R\&I) (Grinbaum \& Groves, 2013; Noorman, 2014; Urbanovič \& Tauginienė, 2013). Therefore, it is vital that it is part of the discourse that takes place with regards to the implementation of successful ICT research projects (Sullins, 2012). One way of achieving the successful implementation of the projects is by engaging stakeholders who assimilate roles that could contribute towards the recognition of responsibility within those projects (Chatfield, Iatridis, Stahl, \& Paspallis, 2017; Frankel, 2015; Sullins, 2012). For instance, in recent years, this view has been supported by the concept of Responsible Research and Innovation (RRI).

Under RRI, stakeholders should have roles that contribute towards the recognition and integration of responsibility in innovation processes within ICT research projects (Bauer, Bogner, Fuchs, Kosow, \& Dreyer, 2016; Jirotka, Grimpe, Stahl, Eden, \& Hartswood, 2017). The engagement of different stakeholders facilitates an open, inclusive and timely exploration of different aspects of the innovation process (B. C. Stahl, Eden, Jirotka, \& Coeckelbergh, 2014). The contribution of stakeholders that are engaged in ICT research projects has the potential to ensure that the outputs and outcomes of R\&I that is taking place in such projects are not detrimental to society's wellbeing (Ayuso, Ángel Rodríguez, García-Castro, \& Ángel Ariño, 2011; Grunwald,
2011). In ICT research projects, it is essential that stakeholders are determined and effectively engaged so that there is a progressive consideration of ethical and social implications of technology innovation and advancement.

Responsibility is an important theme in recent European policy discussions about the future of research and innovation, particularly about new and emergent fields in technology (Owen, Bessant, and Heintz 2013a). The main goal is to maximise the positive and minimise the negative impacts of new technologies such as ICTs, by intervening in the process of their development through more awareness and collective consideration of emerging societal impacts (Stahl, 2012). Most of the societal challenges are pervasive and interconnected. Thus, to effectively resolve them there is need to engage a range of stakeholders in contributing towards the resolution. As part of their contribution, stakeholders offer a range of perspectives and expertise which positively influence the perception and integration of responsibility within ICT research projects.

In this paper, my focus is on understanding how stakeholders are identified to contribute towards responsibility in ICT research projects and how stakeholders contribute towards the assimilation of responsibility in ICT research projects. There has been considerable research on stakeholder contribution towards different aspects of technology such as impact and financial viability. However, there seem to be a gap in research that looks at contribution towards responsibility specifically in ICT research projects. Also, the range of stakeholders is so wide and therefore leads to problems when identifying relevant stakeholders to contribute towards responsibility or

1) Centre for Computing and Social Responsibility, De Montfort University, The Gateway, Leicester, United Kingdom.

${ }^{*}$ Corresponding author: tilimbe.jiya@dmu.ac.uk 
responsible behaviour in ICT research projects. Responsibility is an essential element when carrying out innovative activities within ICT research projects. Therefore, for stakeholders to effectively contribute towards this important element, their roles should be incontrovertibly defined so that they are certain about what is expected of them about responsibility.

To gain such an understanding, I have chosen ICT research projects as the case since they are an important platform for the discovery and exploitation of new technologies that affect society. I used two ICT research projects as case studies. Stakeholders engaged in these projects need to take into consideration the impacts of their activities on society and should find solutions to emerging societal challenges. For that reason, the critical question addressed in this paper is; how do stakeholders that are engaged in ICT research projects contribute towards responsibility in research and innovation?

This paper contributes to the discourse on the social and human aspects of ICT research and innovation by taking a step back and reflecting on how human behaviour influences the process and its outcomes.

\section{Responsibility in ICT research and innovation}

New ICTs that affect individuals and society in many ways are continually being developed through R\&I that is taking place in projects. Although these new technologies have benefits to society, they can have negative consequences too. These consequences are responsibility issues that affect society.

\section{Responsibility}

Responsibility is indispensable and significant at all levels of ICT research and innovation starting from idea generation all the way up to society utilisation of the outputs and outcomes (Auhagen \& Bierhoff, 2001; Lenk \& Maring, 2001). However, although this may sound obvious, there are issues with how responsibility can be understood and integrated into stakeholders' actions and therefore R\&I processes within ICT research projects. One of the issues could be down to the ambiguity of what 'responsibility' means (Pellé \& Reber, 2015) which then affects how one makes reference to it and understands it within an ICT research project.

For instance, responsibility within an ICT research project could be looked at in terms of moral values that are affected by the outcomes of the innovation being developed in that project. Taking this stance translates into having an understanding of responsibility regarding the moral commitment of stakeholders that are engaged in the realisation of these outcomes (Noorman, 2014; Sand, 2016; Sullins, 2012). Another angle could be looking at responsibility within ICT research projects in connection to the social and ethical desirability of the innovation and research process as mentioned in RRI accounts (Guston 2011; Owen et al. 2013b; Von Schomberg 2013; Simon 2017; Jirotka et al. 2017; Stahl et al. 2017). In these accounts, responsibility is looked at in the light of anticipation, reflexivity, responsiveness, transparency and public participation.
With the former, responsibility in ICT research projects could be understood in terms of using morally adequate standards and principles when executing innovation processes complemented by the stakeholders who sensitively accommodate 'accepted' moral values into the processes and outcomes of their project. While with the latter, responsibility in ICT research projects could be looked at regarding an active collective understanding that seeks to prevent harm and identify more positive outcomes for the innovation process (Lenk \& Maring, 2001; Pellé \& Reber, 2015). This distinction between the meanings of responsibility is imperative because it highlights a profound issue with regards to stakeholders' contribution towards responsibility or responsible behaviour. It partly shows how responsibility can variably be understood and interpreted which consequently affects the way it would be regarded as an element of the processes within ICT research projects.

In terms of conception, the notion of responsibility has various constructions that are linked to assignment, attribution and imputation of one's actions or their consequences under the judgement of an agent. The imputation of one's actions is in relation to a 'set of criteria of attribution and accountability within a specific context of responsibility and action' (Lenk \& Maring, 2001, p. 95). In simple terms, responsibility means that stakeholders may be expected to justify situations, actions and their tasks with respect to their obligations and roles according to set standards, criteria and norms (Auhagen \& Bierhoff, 2001). It also covers the capacity and authority of an agent undertaking a certain task and is further understood regarding an agent's accountability, obligation, liability and their link to the causes and outcomes of a particular endeavour (Pellé \& Reber, 2015). These are elements of responsible behaviour in ICT research projects, and stakeholders play a very significant role in influencing such behaviour. This then gives me a departure point to look at who are the stakeholders and how are they engaged to contribute. It is a challenge to integrate responsibility into a project of any type, including an ICT research project if the project fails to understand its stakeholders and their role.

\section{Stakeholder theory}

Stakeholder theory is an approach to recognising and dealing with relationships among stakeholders of a project. There is more literature on stakeholder theory in business, and environmental studies which can be used in technology studies as well since the underlining principles and theoretical underpinnings are transferable and can, therefore, be adopted. In most of the literature, the stakeholder theory is linked to firms and organisations. However, I see no reason to not apply the same to ICT research projects because the general dynamics within a project resemble those of an organisation or a firm. Stakeholder theory can be traced back to the seminal work of Freeman (1984), who articulated a new conceptual model of the firm [the project] that must address the interests of its stakeholders, both groups and individuals who can affect or are affected by the firm's purpose (Röbken, 2013, p. 63).

There is a variance on what defines a stakeholder and the definition of a stakeholder spans across many disciplines and industries. Taking into consideration the definition adopted for this paper, from an ICT 
research project perspective, stakeholders may include researchers, funders, local authorities, civil society organisations and industry players. These are all critical for the ICT research project's survival and success in that they significantly affect how the project is directed and controlled (Freeman, 2010; Lozano, 2005). Because of the variations in defining stakeholders, there are issues and ambiguities when defining roles that are assigned to these stakeholders.

These ambiguities are related to two viewpoints; one that a stakeholder could be defined with regards to the legitimate interest of the prospective agent (person or a group) in the project. However, legitimate interest is subjective and can cause further problems with regards to stakeholder definition. The other viewpoint is that a stakeholder could be defined in terms of a categorisation of a group of members of the society (Carney, Whitmarsh, Nicholson-Cole, \& Shackley, 2009). Despite that these perspectives are fundamental to the ambiguity resulting from the variation in defining stakeholders, they present a reference point in determining who is a stakeholder in an ICT research project. The conceptualisation of a stakeholder is quite broad therefore it can be troublesome when it comes to defining a stakeholder in an ICT research project, leading to confusion and misconception of who is a stakeholder and what role do they assume.

To avoid this misconception, in this paper, a stakeholder will among others include researchers that are engaged in ICT research projects. One reason for this proposition is that researchers should arguably be considered as stakeholders since they can affect or be affected by the outcomes of ICT research projects.

\section{Stakeholder identification and engagement}

Stakeholders may be identified using a stakeholder analysis approach which involves categorising stakeholders in relation to their level of interest, influence and relevance to the project (Leventon, Fleskens, Claringbould, Schwilch, \& Hessel, 2016). This approach has the potential to enhance the effectiveness of the stakeholder identification process in ICT research projects. For instance, regarding influence, stakeholders could be identified to contribute based on of their knowledge and expertise (Rahman, Moonira, \& Zuhora, 2015). Another approach suggested by Reed et al. (2009) distinguish between different mechanisms of stakeholder identification through a typology specifically focusing on stakeholder engagement in research. The typology highlights the notion that different types of stakeholders may be engaged subject to the perceived technical competence and influence on outcomes at different phases of the ICT research project. Using a typology when inviting stakeholders to contribute to ICT research projects aids the clarification of the level of contribution that is expected from those who are assigned certain roles. If the identification of stakeholders and their roles is wrong, the expected contribution will not be very effective to the project (Durham, Baker, Smith, Moore, \& Morgan, 2014).

Having looked at what a stakeholder theoretically entails and how their roles can potentially be identified for ICT research projects, I will now shift my focus to the importance they generally have when engaged in ICT research projects.

\section{Importance of stakeholders engaged in ICT research projects}

From the literature on stakeholder engagement, the following could be deemed as the main reasons why stakeholders engaged in ICT research projects are important with regards to the overall success of the project. The first reason is one of knowledge co-production between stakeholders (internal and external). This co-production of knowledge is often a result of active input from different stakeholders which facilitates mutual learning (Chilvers, 2013). Secondly, different stakeholders contribute in increasing the legitimacy of the technology project. Results from the projects that engaged different stakeholders claim legitimacy compared to one that did not engage relevant stakeholders (Spitzeck \& Hansen, 2010). Thirdly, stakeholders facilitate accountability of significant uncertainties that occur in ICT research projects (Taghian, D'Souza, \& Polonsky, 2015). The fourth reason is that stakeholders influence the success of the project by bringing a wider input based on their different disciplines and background on different perspectives. Lastly, stakeholders inform policy formulation and assist in maintaining the relevance of the project to a policy (Webler et al., 2001). The importance of engaging stakeholders that is discussed here is more generic, and it relates to a higher-level aspect of project success. However, stakeholders may also contribute to more specific lower-level aspects of the project such as the integration of responsibility.

\section{Challenges of engaging stakeholders in ICT research projects}

Notwithstanding the benefits of engaging stakeholders in ICT research projects, there are challenges. Engaging multiple stakeholders' increases costs to the ICT research projects and might make the execution of the projects more complicated, for example, through conflict of interest among the different stakeholders (Carney et al., 2009). In ICT research projects, some internal stakeholders may see the engagement of external stakeholders as a constraint instead of an opportunity (Durham et al., 2014) which then results in a conflict of interest and direction. Another challenge could be that some stakeholders may lack time to engage, or may experience 'stakeholder fatigue', that is, they may feel overloaded with engagement activities. This then adversely affect their willingness to participate and therefore lessen the quality of their contribution (Blok et al. 2015).

In this section, I have looked at how stakeholders are identified in ICT research projects. Stakeholders are influential in technology, and they contribute towards many aspects of ICT research projects despite challenges that could potentially affect the effectiveness of their contribution. In the next section, I will present the method used in the study that informs this paper.

\section{Method}

This section presents the method that was used in the conducting the case study that informs this paper. I discuss the design of the research, the cases and their participants that were involved and the procedure that was used during data collection and analysis. 


\section{Design}

This paper used an interpretive case study to understand how different stakeholders contribute towards the integration of responsibility in ICT research projects. The cases used in this paper were two ICT research projects that addressed ways of improving environmental sustainability through ICT innovation. These projects were selected based on the criteria provided in Table 1 below.

Table 2: Criterion and indicators for selecting case projects

\begin{tabular}{ll}
\hline Criterion & Indicator(s) \\
\hline & The research and innovation in ICT should involve; \\
The project should be an ICT research project that is involved & $\begin{array}{l}\text { Stakeholder communication processes. } \\
\text { Innovation processes that deal with societal challenges. }\end{array}$ \\
with research and innovation in ICT in the UK. & $\begin{array}{l}\text { The development of new technology that will tackle social challenges. } \\
\text { The development of new methodologies that will deal with social impacts. }\end{array}$
\end{tabular}

\section{Cases}

Five ICT research projects were identified as potential cases and using the criteria presented in Table 1 above, two ICT research projects were selected for the interpretive case study. The cases have been anonymised by using naming codes and are described in Table 2 below.

Table 2: Case ICT Research Project Descriptions

\begin{tabular}{ll}
\hline Case & Description \\
\hline & $\begin{array}{l}\text { The focus of IT was the use of ICT in developing a dynamic traffic management system across 'city X'. The purpose of IT was to research } \\
\text { and develop an innovative way for optimising the use of the road network while meeting growing demands to sustain high standards of air } \\
\text { quality in urban environments. The ICT research project involved developing a system concept around an existing operational traffic control } \\
\text { system that was already in use in one of the UK cities. The system was augmented with traffic flow and air quality information and near } \\
\text { real-time data from space and in situ measurements }\end{array}$ \\
& $\begin{array}{l}\text { SS aimed to research the use of ICT in promoting environmental sustainability. SS focused on how carbon dioxide emissions from buildings } \\
\text { could be monitored and consequently reduced. The project was involved in energy use optimisation through a comprehensive approach to } \\
\text { exploiting the potential of ICT. As part of the optimisation, the research employed the use of smart metering to achieve significant energy saving } \\
\text { in public buildings. To accomplish this aim, the research project built on existing services to develop a comprehensive ICT system (sometimes } \\
\text { referred to as a 'dashboard') that provides feedback on energy consumption and information for organisational energy management. The system } \\
\text { used ICT to offer access to energy consumption data and provide the results of the sophisticated data analysis intuitively and engagingly }\end{array}$ \\
\hline
\end{tabular}

\section{Participants}

Emails requesting participation in the study were sent to 26 study participants who were involved in the two ICT research projects described in Table 2 above. The potential study participants included four industry representatives, seven researchers, two project sponsor, two principal investigators, three software designer and two advisors and six local authority representative. Out of the 26 stakeholder study participants, 11 participated in the interviews. The others either never responded or cancelled their interview arrangements. The study participants were recruited based on the criteria shown in Table 3.

Table 3: Criteria for selecting study participants

\begin{tabular}{ll}
\hline Criteria & Indicator \\
\hline A participant should be from a relevant context & $\begin{array}{l}\text { Engaged in an ICT research project that is taking place at a recognised re- } \\
\text { search institution or organisation in the UK. }\end{array}$ \\
\hline A participant should comprehend the language used in the research & $\begin{array}{l}\text { Should understand both written and spoken English since this study is con- } \\
\text { ducted in that language. }\end{array}$ \\
\hline $\begin{array}{l}\text { A participant should have a stakeholder role in the ICT research project } \\
\text { whether as an external or internal stakeholder. }\end{array}$ & $\begin{array}{l}\text { Should be a member of civil society, policy-making organisation, research } \\
\text { institutions, academia and funding organisation. }\end{array}$ \\
\hline A participant should be accessible during the data collection phase of the research. & Should be accessible in person, by telephone or VOIP (e.g. Skype). \\
\hline & Should consent to be interviewed. \\
\hline
\end{tabular}




\section{Procedure}

Two key stakeholders from each case ICT research project were purposively sampled. Once the key stakeholders were sampled, using a snowballing sampling technique, these stakeholders suggested others for potential participation in the case study. The study participants took part in semi-structured interviews that lasted between $45 \mathrm{~min}$ utes to 1 hour. The interviews were held at places of convenience for the study participants to ensure having as many study participants as possible. The interviews focused on understanding how the stakeholders got engaged in the ICT research projects and how they felt that they contributed towards integrating responsibility in their respective projects. All the interviews were recorded and transcribed before being uploaded to Nvivo qualitative data analysis software for storage and analysis.

\section{Data analysis}

The analysis process was based on a thematic analysis (Patton, 2002). First, I developed a coding scheme based on the main themes that were identified from the research question. Using the identified themes, data were then grouped under the main themes which included; understanding responsibility, stakeholder identification and form of stakeholder contribution. While these broad categories were initially based on the research question, sub-categories to populate these categories were inductively identified from the transcription through initial coding in Nvivo software. The first stage of the data analysis was a careful reading of the interview transcripts from which a thematic outline was developed which included code classification and justification for the code. Data were extracted from the transcripts and summarised into a series of nodes that represented the categories and sub-categories identified at the beginning of the data analysis. New nodes emerged during the second and third iteration of coding. The second stage of the data analysis involved grouping the nodes and developing them into theoretical constructs based on their relevance and similarity in meaning until no new thematic meanings were emerging from the text. These constructs were the findings from the study, and they are discussed in the following section.

\section{Findings and Discussion}

In this section, I discuss the findings from the case study. The findings are categorised into three main areas that consist of stakeholder identification, the contribution of stakeholders towards responsibility and barriers to stakeholder contribution towards responsibility.

\section{Stakeholder identification}

As discussed earlier, there is ample literature on how stakeholders are identified in different projects (Durham et al., 2014; Reed et al., 2009). However, regarding identifying stakeholders to contribute towards responsibility in ICT research projects, some relevant themes emerged. These themes included the time of stakeholder identification, who identifies the stakeholders and issue with identifying stakeholders with regards to responsibility.

\section{Time of identification}

The time at which stakeholders are identified and defined is crucial in ICT research projects because it influences the level of the stakeholders' contribution towards responsibility in a project. From the study, I found that stakeholders are more often identified, and their roles defined in advance at the inception phase of ICT research projects. Identifying stakeholders and their roles pre-project works well at the early stages of the projects because it helps to lay down the foundations of the projects and recognise roles that will put the projects into motion and integrate responsibility from the word go. However, as the projects progress there should be new stakeholders identified to deal with ad-hoc needs. In terms of responsibility, identifying stakeholders ad hoc could be a better approach in dealing with emerging issues that innovative ICTs may pose to the society.

\section{Who is in control for identifying and defining stakeholder roles}

Another important thing to consider in identifying and defining stakeholders is the question of who should do it. Regarding responsibility, this is crucial because if those designated to identify and define roles are not very familiar with potential responsibility issues relating to the processes, outputs and outcomes of the ICT research projects, they can miss out on engaging appropriate stakeholders. As Durham (2014) suggested, this could result in the projects having negative impacts. From the study, it was learnt that stakeholders are better identified, and their roles defined if the processes are a result of combined thoughts and ideas from the project initiators and other stakeholders rather than an individual. This was highlighted in one of the responses where a stakeholder alleged that;

...the identification of stakeholders and their roles was a combination of my ideas together with XXX's ideas...-IT01

To support the above statement, it was also learnt that there was an agreement by all project parties to include certain stakeholders within the ICT research projects who should look at specific aspects of the projects. This was revealed by these two responses from the interviews where study participants were asked about their involvement in identifying and defining stakeholder roles;

The first respondent said that;

I was in the process ... well, I helped shape the proposal, therefore helped shape stakeholder roles...at the proposal stage, I helped change the roles but then after that I wasn't involved ...-IT02

While the second alleged that;

We worked together with people involved in XXX, in XXX University and so we put the proposal [with the proposed roles] together to EMDA.... -SS01

Such a collective approach in identifying stakeholders and defining their roles ensures that there is a consensus among the parties 
involved in determining which roles are ideal for the projects' aspects such as responsibility in innovation. In addition to taking a collective approach, care should be taken on the level of explicitness in defining the roles so that there is a sustainable buy-in among the stakeholders. One benefit resulting from explicitly defining roles is that it minimises confusion among stakeholders regarding their respective roles in the ICT research projects. This means that to achieve a considerable level of explicitness and therefore reduce confusion and at the same time increase buy-in from the stakeholders on the identified roles, there should be a substantial level of stakeholder involvement in role identification and definition process at the pre-project phase.

Contrary to consensual role determination, the study showed that identifying stakeholders and defining roles could sometimes be 'naturally' endowed to the people who propose the project and have a high level of influence and interest on the ICT research project and its objectives. In determining who should define roles, a stakeholder analysis based on the stakeholder's influence gauged against their interest, as suggested by Durham (2014) and Leventon et al. (2016) can be used to identify those to collaborate and involve in identifying new stakeholders and what roles they should take. However, this could only work well if the project is small and involve a small number of stakeholders otherwise there is a risk of conflict and confusion among the stakeholders undertaking the identified roles.

It is worth pointing that every ICT research project is unique and is a construct of some issues that need to be considered such as decision-making processes, the culture of the project, context and aims. All these may affect which stakeholders can be and cannot be involved in contributing to certain aspects of the project, for instance, responsibility. Therefore, understanding some of these issues will ensure that the appropriate stakeholders who are relevant to contribute towards responsible behaviour within ICT research projects are identified.

\section{The problem with identifying stakeholders with regards to responsibility}

In the study, it was acknowledged that the problem of stakeholder identification becomes more complicated and ambiguous when it comes to identifying stakeholders that deal with responsibility due to a misapprehension of the concept. An issue that was apparent from the study was the lack of knowledge or understanding of the terms 'responsibility' or 'responsible innovation'. The apprehension of these terms is a prerequisite to effectively define stakeholders that will directly deal with them as is the case with any other aspects of the ICT research project that stakeholders could potentially be engaged for. However, in agreement with Pellé and Reber (2015), I learnt that stakeholders did not understand ' $r e$ sponsibility' per se, therefore, found it difficult to give their opinion and could not articulate what their expectation was regarding contributing towards responsible behaviour in an ICT research project. Hence, from the interviews, two problems that affect stakeholders' expectation of their contribution towards responsibility were identified. These included ambiguity of what responsibility or responsible behaviour meant and the lack of knowledge about a clear connection between their roles and responsible behaviour.
This highlights a crucial point with regards to contributing towards responsibility, in other words, responsible behaviour in ICT research projects. What is crucial here, is a need for a wider awareness of the concepts of 'responsibility' or 'responsible innovation' and any other related concepts to stakeholders within ICT research and innovation so that they understand it more and embrace it without uncertainty. A bit of clarity on the use of terms could make it easier for stakeholders in ICT research projects to understand what their expectations are within the project with regards to promoting responsible behaviour or responsibility. To incontrovertibly and effectively identify stakeholders to support responsibility, it is crucial that they understand what responsibility in an ICT research project entails. Otherwise, their contribution becomes inadequate and has implications for stakeholders' expectations.

Concerning this study's participants, they struggled to talk about their contribution regarding responsibility because they did not clearly understand the term. This correlates with the notion that there are a number of definitions or descriptions of responsibility (Auhagen \& Bierhoff, 2001; Lenk \& Maring, 2001) therefore it is not surprising to establish that there is confusion among stakeholders in ICT research projects caused by its conception. Evidence of the issue with understanding is shown in one of the responses when study participants were asked about their contribution towards integrating responsibility;

Good question. Can you remind me ... responsible innovation ... responsibility in terms of the outputs of it ...or what? What do you mean by responsibility? - SS03

This could indicate that either the concept of responsibility in terms of responsible innovation was novel and therefore was not known to them or they had more interest in other aspects other than responsibility that was directly linked to the final outputs of the ICT research projects. The responses from the interviews indicated that the use of the term was ambiguous for their comprehension. It also was found that there was a divide in the apprehension of the term, with one interviewee giving an impression that they perhaps knew what responsibility in innovation involves due to their prior experience and knowledge of the term while the other had no clear apprehension. There was clearly a semantic confusion about the word responsibility, and it was looked at in terms of both as an obligation and attribution for the stakeholder (Lenk \& Maring, 2001; Pellé \& Reber, 2015). Comparatively, responsibility was partly understood as a requirement to carry out tasks as part of a duty that would result in responsible outcomes and therefore contributing towards responsibility in ICT research projects. This was shown in the following response where the interviewee was asked about their contribution towards responsibility within the project;

...my responsibility was to implement a demonstrator to prove the feasibility of XXX. I guess the contribution towards responsible innovation is the air quality side of things ....my role was to look at ways how we could come up with a methodology that would combine these different objectives and deliver something that actually gives an output that will change lives... may potentially change lives by reducing air quality and at the same time reducing traffic congestion - IT02. 
A response such as one above indicates that the contribution of stakeholders towards responsibility could also be better understood in terms of the project's processes and outputs. Therefore, to ascertain an integration of responsibility or responsible behaviour in ICT research projects, one could look at how the process is being carried out and then look at the project's outcomes for instance, in relation to societal impacts.

\section{How stakeholders contribute towards responsible innovation}

From the study, some ways through which stakeholders contribute towards responsibility in ICT research projects were brought to light. The contributions were either directly or indirectly and are discussed below.

\section{Provision of expert knowledge}

The study participants in the interviews mentioned expertise as one way of contributing towards responsibility. Through their expert knowledge, stakeholders suggest innovative ways that can bring forth a public good from their research activities and outcomes. For instance, one of them said that they had to use their expert knowledge to come up with a methodology and design for improving air quality through a traffic management system. The stakeholders' expert knowledge is one of the crucial elements to consider when contributing to responsibility in ICT research projects as can be evidenced by this response;

... am an expert in the area of XXX. I work with optimisation... what was needed for the role was somebody who can design a system that could ensure a sustainable environment.... -SS04.

\section{Sharing experiences}

Different stakeholders contribute towards responsibility in ICT research projects by sharing their experiences to capitalise on the power of combining perspectives from a spectrum of capabilities. This was substantiated by the following responses from the study participants;

We had to combine my knowledge with the knowledge of $\mathrm{XXX}$ and the knowledge of XXX to come and make something that will make a difference in the world. -SS07

Engaging various stakeholders gather knowledge and cultivate different perspectives on how certain social problems could be solved and how to behave to mitigate the problems. In ICT research projects where different roles are assigned, stakeholders that have different backgrounds and experiences, therefore, different perspectives could be considered to have solutions to problems relating to certain aspects of the project. These different stakeholders bring with them new and unique perspectives on how certain issues could be resolved. So, with regards to responsibility, having a unique perspective on solutions require stakeholders to collectively think outside the norm and start looking at certain elements of the ICT research project such as objectives and outputs, in light of social impact and responsible innovation.

\section{Provision of advice}

The study participants stated that they provided advice on carrying out the projects' processes to attain outputs responsibly. The advice included directing procedures of the innovation process to have a positive social impact. These procedures involved developing methodology designs which could ensure that responsibility is upheld throughout the project's activities, which then translated to responsible and sustainable outcomes from the ICT research projects. In the study, one of the respondent's role was to give advice in steering the processes of the project towards achieving outputs that have a greater positive impact on society and at the same time ensuring that there were no deviations from achieving other objectives of the projects.

\section{Provision of resources for promoting responsible behaviour}

For ICT research projects to integrate responsibility, there should be access to resources for promoting the agenda. These resources range from human resources to financial resources. Talking to the study participants, I found that funding is an important element of ICT research projects and that certain stakeholders are engaged to pool their resources both financial and human to promote responsibility in ICT research projects. As an example, from the study, an industrial stakeholder contributed financially by funding part of the project and its activities. Successful integration of responsibility in ICT research projects depend on the availability of resources that can be directed towards efforts that will ensure prioritisation of responsibility as part of the objectives of the project as said by one respondent;

So, the outcome of my contribution could be cost saving [...] my contribution towards behavioural change [...] for example switching lights at night. -SS03.

\section{Barriers to stakeholders' contribution towards responsibility}

Having looked at how stakeholders contribute towards responsibility in ICT research projects, I turn my focus on some of the barriers to stakeholders' contribution towards responsibility. From the study, I found that they are hindrances to integrating responsibility in ICT research projects as discussed below.

\section{Dissimilarity in the way stakeholders do things}

The first barrier to stakeholders' contribution towards responsibility within ICT research projects is the differences in the way engaged stakeholders do things. This affects the consensus on determining responsibility priorities and responsible processes within the project. The dissimilarities could be down to a variation of backgrounds and intentions of the stakeholders, which later affects the attitudes towards responsibility and prioritisation of its implementation. Also, due to the dissimilarities, misunderstandings among stakeholders emerge which then affect the way they would implement and ensure responsibility or at least contribute towards it. 


\section{Stakeholder non-commitment}

The second barrier is the let downs among stakeholders who are assigned roles. Stakeholders can frustrate each other by not providing the necessary input that is necessary for the integration of responsibility such as data, information and materials that are required by others to fulfil their tasks. As said earlier, stakeholders need to be collaborative to implement responsibility effectively, however, stakeholders that are entrusted with roles can let each other down in many ways. For instance, it was highlighted in the study that some stakeholders were not providing resources such as data, as they promised, therefore, affecting the interim outcomes of the project. In other cases, the resources shared were sometimes not as valuable as expected, rendering them inadequate for purpose as evidenced in this response;

...there were a few friends gathering the data [who] would promise... but sometimes the data was not really valuable as we thought. It, therefore, had an impact on the modelling that we developed.- SS04.

\section{Stakeholder scepticism}

The third barrier in integrating responsibility in ICT research projects is related to fear of change. From this study, it was mentioned that 'people fear change' (SS02) and some stakeholders could be sceptical when it comes to contributing towards integrating responsibility because it is a change that alters the stakeholders' way of doing things when executing project processes as one of the interviewees put it;

Responsibility in innovation requires people to look outside of the box or to accept change, and that is probably the biggest problem when it comes to such projects in terms of innovation...- SSO3

As a result of the fear of change or what may transpire from the change, stakeholders are comfortable to maintain the status quo which jeopardises the integration of responsibility and ultimately responsible innovation within ICT research projects.

\section{Unforeseen resource constraints}

Another barrier to contributing towards responsibility within ICT research projects is resource deficits or changes that are unforeseen. These resources could include among other things time and funds for activities that could have an impact on contributing towards integrating responsibility. This was pointed out in the interviews by one of the study participants when they were asked about the barriers encountered during the project that could have affected its execution responsibly. The respondent alleged that;

Another hurdle that we went through was that we had to run an extension of the project for two years... the company that we were working with was running through some economic problems...-IT02.
This indicates that the availability of resources could limit the contribution of stakeholders engaged in ICT research projects which then potentially results in cutting corners when executing the processes and therefore overlooking important elements that could impact society.

\section{Lack of stakeholder compulsion}

Due to the unfamiliarity with the terms 'responsible innovation' or 'responsibility', stakeholders are inclined not to appreciate the need for integrating responsibility in the first place. Stakeholders will find it difficult to appreciate the need for responsibility or responsible innovation in ICT research projects until the notion is widely seen as a crucial requirement in ICT research projects. However, with the policy push by governments towards policies on responsible innovation such as RI (Murphy, Parry, \& Walls, 2016) and RRI (Stahl, Timmermans, \& Flick, 2016) a lot of stakeholders will start appreciating the need to implement responsibility in ICT research projects consistently.

\section{Prioritising other aspects}

The last barrier to integrating responsibility in ICT research projects is stakeholders' consideration of other aspects of the project to be of more significance than responsibility. The priority could be towards other aspects such as cost reduction and rapid output production (Schenke, van Driel, Geijsel, Sligte, \& Volman, 2016). According to one study participant, this is the biggest barrier as they found out in their project;

Unfortunately, very often [responsibility] is not enough. What is enough is if there is a cut in cost or if there is a policy that requires it. Possibly it's important if somebody big enough says that, ok [...] this is what we are supporting, but it's very difficult, and that's the biggest obstacle I would say - SS05.

Integrating responsibility within ICT research projects is likely to be compromised to satisfy other prioritised aspects depending on the level of buy-in to the need for responsibility from both the project sponsors and influential stakeholders. This could culminate in corners being cut to push for final outputs and fulfil the objectives of the prioritised aspects with disregard to the social impact of their outputs.

In a nutshell, the above discussion means that contributing towards responsibility in ICT research projects is not smooth sailing, but some obstacles get in the way. However, although this is the case, these hindrances could be circumvented by effective stakeholder engagement.

\section{Conclusion}

To conclude, in this paper I have discussed how stakeholders that contribute towards responsibility in ICT research projects could be identified. Understanding how they are identified, and their roles defined is very crucial in engaging stakeholders that will perhaps contribute towards responsibility in ICT research projects in an effective manner. When ICT research projects are being implemented, some expectations must be met about specific aspects such as finance or responsibility. Therefore, stakeholders need to be identified particularly regarding how they will contribute towards the expectations. This is 
a problem when stakeholders are identified to contribute towards the integration of responsibility in ICT research projects mainly due to the nature of responsibility and how its meaning can be understood by different stakeholders. This shows that part of the problem with the stakeholders contributing towards responsibility in ICT research projects is down to the level of clarity about the rationale for engaging them in the first place. It was surprising to learn that those engaged in ICT research projects do not easily understand what is meant by 'responsibility' in technology innovation when the term is used without further explanation of its meaning. This misapprehension, in turn, affects the stakeholders' understanding of how they contribute towards this important aspect of ICT research projects. Nevertheless, once the meaning of the term is clear, it is evident that stakeholders contribute towards responsibility in many ways although there are barriers that affect their contribution. Therefore, the overall conclusion here is that stakeholders are integral to the integration of responsibility in ICT research projects although their contribution is implicit due to the nature of responsibility.

\section{References}

Auhagen, A. E., \& Bierhoff, H. W. (2001). Responsibility: The Many Faces of a Social Phenomenon. Routledge.

Blok, V. (2014). Look who's talking: responsible innovation, the paradox of dialogue and the voice of the other in communication and negotiation processes. Journal of Responsible Innovation, 1(2), 171-190. https://doi.org/10.1080/23299460.2014.924239

Blok, V., Hoffmans, L., \& Wubben, E. F. M. (2015). Stakeholder engagement for responsible innovation in the private sector: critical issues and management practices. Journal on Chain and Network Science, 15(2), 147-164. https://doi.org/10.3920/JCNS2015.x003

Carney, S., Whitmarsh, L., Nicholson-Cole, S. A., \& Shackley, S. (2009). A dynamic typology of stakeholder engagement within climate change research. Tyndall Center for Climate Change Research, Working Paper, 128. Retrieved from http://www.tyndall.ac.uk/sites/ default/files/wp128.pdf

Durham, E., Baker, H., Smith, M., Moore, E., \& Morgan, V. (2014). The BiodivERsA Stakeholder Engagement Handbook. Paris: BiodivERsA. Retrieved from http://www.biodiversa.org/698/download

Freeman, R. E. (2010). Strategic Management: A Stakeholder Approach. Cambridge University Press. Retrieved from https://books. google.co.uk/books?id=NpmA_qEiOpkC

Guston, D. H. (2011). Participating Despite Questions: Toward a More Confident Participatory Technology Assessment: Commentary on: "Questioning 'Participation': A Critical Appraisal of its Conceptualization in a Flemish Participatory Technology Assessment". Science and Engineering Ethics, 17(4), 691-697. https://doi.org/10.1007/s11948-011-9314-y

Lenk, H., \& Maring, M. (2001). Responsibility: The Many Faces of a Social Phenomenon. (A. E. Auhagen \& H. W. Bierhoff, Eds.). Routledge.
Lozano, J. M. (2005). Towards the relational corporation: from managing stakeholder relationships to building stakeholder relationships (waiting for Copernicus). Corporate Governance: The International Journal of Business in Society, 5(2), 60-77. https://doi. org/10.1108/14720700510562668

Murphy, J., Parry, S., \& Walls, J. (2016). The EPSRC's Policy of Responsible Innovation from a Trading Zones Perspective. Minerva. https://doi.org/10.1007/s11024-016-9294-9

Nathan, G. (2015). Innovation process and ethics in technology: an approach to ethical (responsible) innovation governance. Journal on Chain and Network Science, 15(2), 119-134. https://doi.org/10.3920/ JCNS2014.x018

Owen, R., Bessant, J. R., \& Heintz, M. (Eds.). (2013a). Responsible innovation: managing the responsible emergence of science and innovation in society. Chichester, West Sussex: John Wiley \& Sons Inc.

Owen, R., Bessant, J. R., \& Heintz, M. (Eds.). (2013b). Responsible innovation: managing the responsible emergence of science and innovation in society. Chichester, West Sussex: John Wiley \& Sons Inc.

Patton, M. Q. (2002). Qualitative research and evaluation methods (3rd ed.). Thousand Oaks, CA.

Pellé, S., \& Reber, B. (2015). Responsible innovation in the light of moral responsibility. Journal on Chain and Network Science, 15(2), 107-117. https://doi.org/10.3920/JCNS2014.x017

Reed, M. S., Graves, A., Dandy, N., Posthumus, H., Hubacek, K., Morris, J., ... Stringer, L. C. (2009). Who's in and why? A typology of stakeholder analysis methods for natural resource management. Journal of Environmental Management, 90(5), 1933-1949. https://doi. org/10.1016/j.jenvman.2009.01.001

Röbken, H. (2013). Inside the "Knowledge Factory": Organizational Change in Business Schools in Germany, Sweden and the USA. Deutscher Universitätsverlag. Retrieved from https://books.google.co.uk/ books?id=cUMBCAAAQBAJ

Stahl, B. C. (2012). Responsible research and innovation in information systems. European Journal of Information Systems, 21(3), 207-211.

Stahl, B. C., Timmermans, J., \& Flick, C. (2016). Ethics of Emerging Information and Communication Technologies: On the implementation of responsible research and innovation. Science and Public Policy, scw069. https://doi.org/10.1093/scipol/scw069

Sullins, J. (2012). Information Technology and Moral Values. Retrieved from http://stanford.library.usyd.edu.au/archives/fall2013/entries/it-moral-values/

Von Schomberg, R. (2013). A vision of Responsible Research and Innovation. In R. Owen, M. Heintz, \& J. Bessant (Eds.), Responsible Innovation. London: John Wiley. 
